\title{
Thermographic method to locate concealed defects in Exterior Wall Insulation Panels of Prefabricated Houses
}

\author{
Veronika Putz ${ }^{1}$, Richard Schmidt ${ }^{1}$, Simon Haunschmid ${ }^{2}$, Christian Kastl ${ }^{1}$ \\ ${ }_{1}^{1}$ Linz Center of Mechatronics GmbH, Altenberger Straße 69, 4040 Linz, Austria \\ 2 Synthesa Chemie Gesellschaft m.b.H., Dirnbergerstraße 29-31, 4320 Perg, Austria \\ Veronika.Putz@lcm.at
}

\begin{abstract}
Summary
This contribution proposes using passive thermography to locate concealed defects in the exterior wall insulation of prefabricated houses, which may lead to spots with higher residual moisture. The method can be applied within approx. 3 days after plastering. Its usability is illustrated in several experiments.
\end{abstract}

Keywords: Non-destructive Testing, Quality Control, Thermography, Image Processing

\section{Introduction}

In prefabricated house construction, wall modules are fabricated in a factory hall, transported to the building site, and assembled. At the production site, a high degree of prefabrication is achieved: For example, all layers of a loadbearing exterior wall in timber frame construction, including vapor barrier, facade insulation (panels e.g. made of polystyrene), exterior plaster and a fiber glass reinforcement grid, can be assembled in the factory building. After construction, the modules are left in an indoor interim storage for drying before they are transported to the building ground. Due to space constraints, storage time needs to be as short as possible. However, to avoid damages during transportation, the plaster needs to be sufficiently dry before loading. Caused by local thickness variations of the plaster, spots with higher residual moisture may remain. Thickness variations occur at local defects (e.g. dents with depths of a few $\mathrm{mm}$ caused by storage and handling) of the underlying insulation panels or height deviations and gaps between neighboring panels. In this contribution, an NDT method to locate areas with residual moisture using thermography, which allows assessing concealed defects after plastering, is presented.

\section{Measurement Principle and Setup}

Freshly applied plastering material dries by the evaporation, which (without external heating) cools the plaster (evaporation cooling [1]). If a plastered wall is inspected in the infrared (IR) domain, moist segments are colder than dry areas. Applications of the method lie e.g. in the inspection of historic masonry [2] or in the detection of water damages in buildings. To adapt for locating small geometric errors in prefabri- cated exterior walls, an IR camera with high sensitivity is required ${ }^{1}$.

\section{Experiment 1: Plaster thickness and plaster material type}

To measure the influence of layer thickness and different plaster types, the following sample was prepared: Three polystyrene panels with different heights $\left(h_{1}=10.7 \mathrm{~mm}, h_{2}=10.55 \mathrm{~mm}\right.$, and $\mathrm{h}_{3}=10.8 \mathrm{~mm}$ ) were aligned on a wooden carrier panel, then plastered by trained craftsmen. A layer of fiber reinforcement grid was wrought into the plaster. Three types of plaster (A: Capatect CarbonSpachtel, B: Capatect CarboNit Easy, C: Capatect CarbonSpachtel Easy, see [3] for details) were applied ${ }^{2}$. Figure 1 shows a cross-sectional and a top view of the sample: The boundaries between segments of different plaster thickness (boundary type 1) and segments of different plaster material (boundary type 2) were arranged orthogonal to each other. The plastered sample was monitored for $120 \mathrm{~h}$ while drying (an IR image was captured every 30s) in an empty and windowless room with stable room temperature and humidity. To reduce image noise, the images were averaged across 30 consecutive recordings, yielding a temporal resolution of $15 \mathrm{~min}$. In the processed data, in the first $15 \mathrm{~h}$, neither thickness nor material boundaries are visible. Between 24h and 48h, segments with different thickness can clearly be distinguished. Areas covered with plaster $C$ strongly deviate from areas covered with types A and B (Fig. 2).

\footnotetext{
${ }^{1}$ Optris PI 450i (spectral range 7.5 to $13 \mu \mathrm{m}$, sensitivity $40 \mathrm{mK}$, resolution $382 \times 288$, field of view: $53^{\circ} \times 40^{\circ}$ )

${ }^{2} \mathrm{~A}$ sharp transition between the three plaster types was achieved using masking tape, which was removed after applying the plaster.
} 
a)

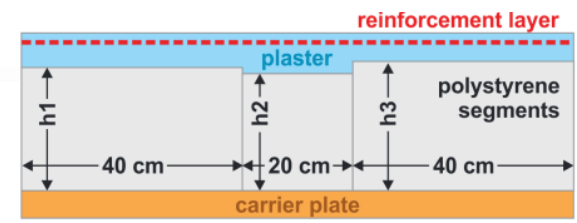

b)

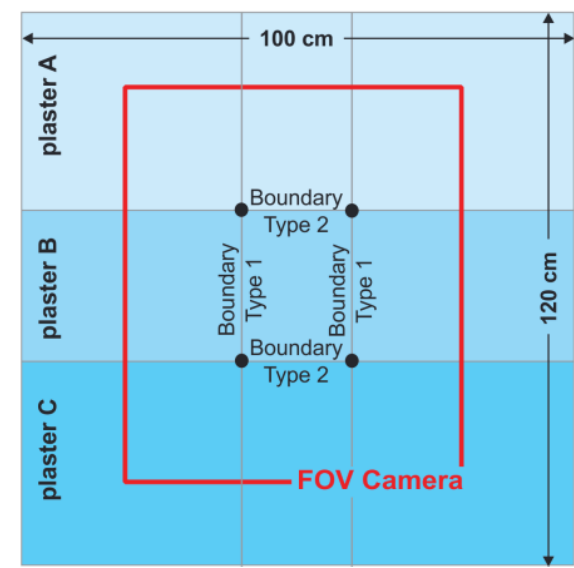

Fig. 1. Cross-section (a) and top view (b) of the sample used in Experiment 1 (not drawn to scale)

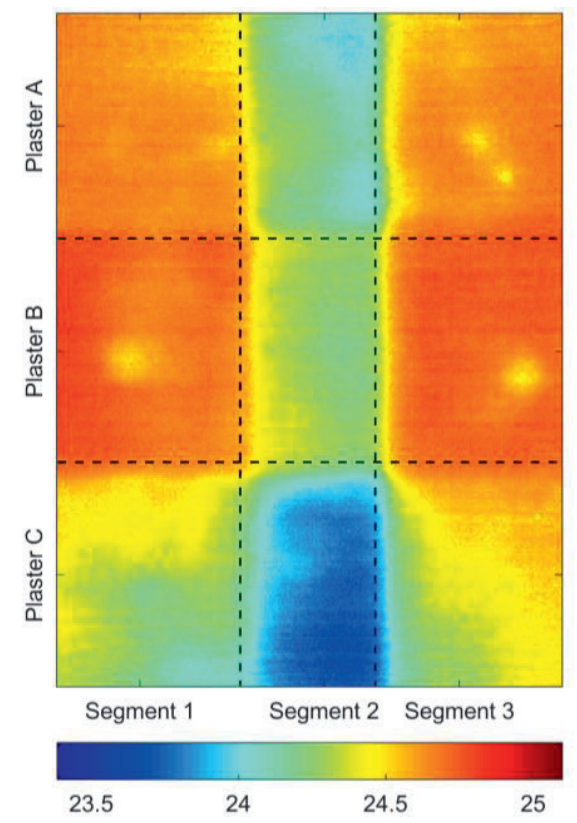

Fig. 2. Processed thermal image (captured $48 \mathrm{~h}$ after start, all temperatures are color-coded in ${ }^{\circ} \mathrm{C}$ )

\section{Experiment 2: Detecting smooth defects}

To verify the proposed method for detecting flat defects with smooth contour, a polystyrene plate $(25 \times 25 \times 5 \mathrm{~cm})$ was damaged with a hot air gun, yielding 4 dents with depths between 1 and $2 \mathrm{~mm}$ ). The plate was fit into a wooden frame and plastered (type A, see Fig 3). Again, the IR camera was used to monitor the sample. Figure 4 shows the images after preprocessing (averaging, detrending using the Gauss-Newton method, see e.g. [4]). 30 hours after plastering, the dents are visible, best results are achieved 48 hours after plastering. Even after 66 hours, the defects can be detected, although the measured temperature deviations are small. a)
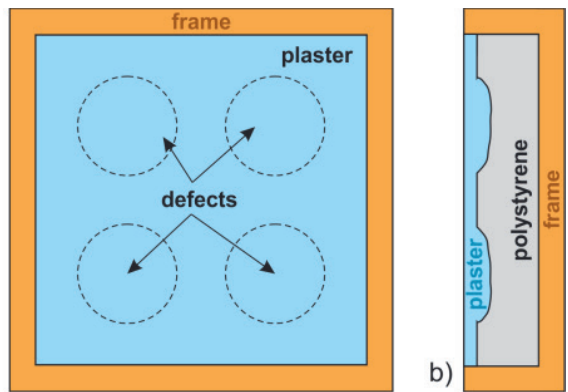

Fig. 3. Top view (a) and cross-sectional drawing (b) of the sample used in Experiment 2
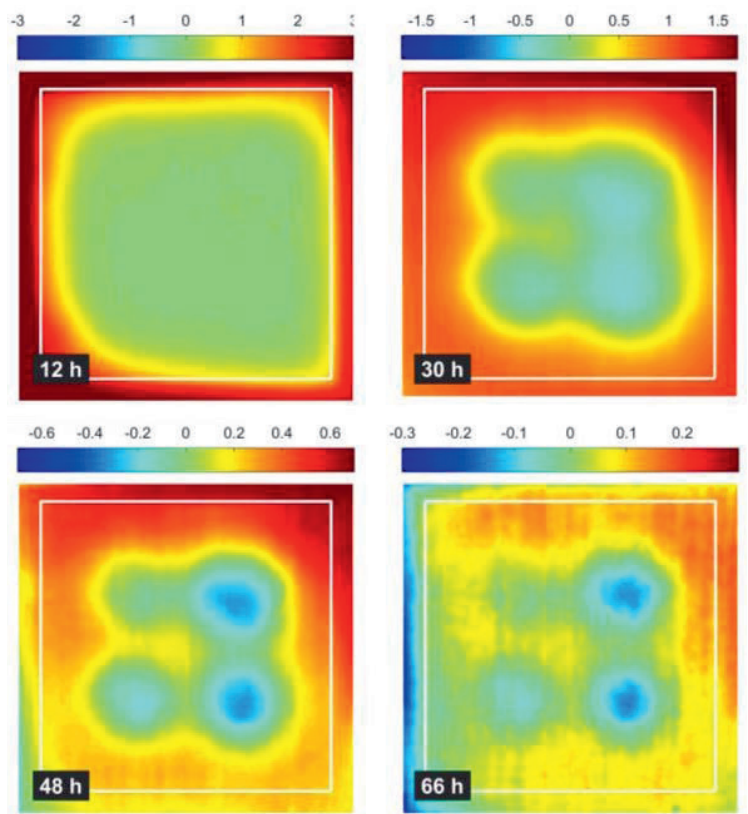

Fig. 3. Processed thermal images

\section{Conclusion and Outlook}

The proposed method obtained promising results in two experimental settings. Upcoming experiments will include measurement using a complete wall segment in a realistic setting.

\section{Acknowledgement}

This contribution was partly carried out within a cooperative research project, funded by the Austrian Research Promotion Agency (FFG, Grant No. 864811). It has furthermore been supported by the COMET-K2 "Center for Symbiotic Mechatronics" of the Linz Center of Mechatronics (LCM) funded by the Austrian federal government and the federal state of Upper Austria.

\section{References}

[1] D. Meschede, Gerthsen Physik, 24 $4^{\text {th }}$ edition, Springer, 2010.

[2] M. Solla et al. "A multidisciplinary non-destructive approach to analyze moisture in historic masonry structures," in $14^{\text {th }}$ Int. Conference on Ground Penetrating Radar (GPR), 2012.

[3] www.synthesa.at

[4] E. Chong et al. An introduction to optimization. John Wiley \& Sons, 2004. 